\title{
IT Governance from Theory to Practice: The importance of accountability
}

\author{
Dr. Marie Griffiths \\ Salford Business School \\ University of Salford \\ Salford, UK \\ m.griffiths@salford.ac.uk
}

\author{
Leena Janahi \\ Salford Business School \\ University of Salford \\ Salford, UK \\ I.a.m.janahi@edu.salford.ac.uk
}

\author{
Dr. Hesham Al-Ammal \\ College of IT \\ University of Bahrain \\ Sakheer, Kingdom of Bahrain \\ heshaaam@gmail.com
}

\begin{abstract}
It is widely acknowledged that Information Technology (IT) Governance is extremely complex and at the same time equally critical when organisations endeavour to maximize their IT investments. IT Governance provides the means for decision making required to ensure that IT enables the organization to excel in its mission. IT systems are often viewed as monetary drains rather than seen as fundamental bases underpinning the strategic direction of organizations. IT implementations often do not meet requirements, fail, are over budget and the media is littered with headlines that corroborate these perceptions. IT projects are now so big, and they touch so many aspects of an organization, that they pose a singular new risk as according to Harvard Business Review Magazine that a $\$ 5$ million project leads to an almost $\$ 200$ million loss (Flyvbjerg and Budzier, 2011). Every organisation will have experienced complications of an IT implementation and this is why IT Governance is becoming a crucial factor to business survival no matter how large or small an organisation is. This interpretive study of IT Governance provides an opportunity to from both theoretical and practice-based perspectives using multiple case studies from public sector organisations based in the Kingdom of Bahrain.
\end{abstract}

Keywords_-IT; Governance; COBIT; Maturity Model; Alignment; IT Risk; accountability

\section{INTRODUCTION}

IT Governance has been viewed from diverse perspectives and is still considered as a subject of debate since the late nineties when attention was given to Corporate Governance as a response to the Enron and WorldCom collapse (Denise Ko, 2010). Information Technology is fundamental for sustaining business growth and has acquired a critical role in improving Corporate Governance practices. Therefore, IT managers must be aware of the critical IT risks and its controls for significant decision-making over IT. The importance of IT Governance can be viewed from the focus of IT cost and value. In this scope the authors in (W.Ross, 2004) state that "IT value depends on more than good technology". Similarly, (Webb, 2006) state the example that "IT baseline costs are significant and rising. It has been reported that they make up about $75 \%$ of the operating budget and represents approximately $4 \%$ of gross revenue". In some countries, for instance organisations in North America and Western Europe, have increased investment in IT and focused on ensuring that IT delivers value around $4.2 \%$ of the annual revenues (Clementi et al., 2006). In general, worldwide IT spending reached $\$ 3.4$ trillion in 2010 with 4.6 percent increase from 2009 (Norshidah Mohamed, 2012). Therefore, organisations need to protect information assets from any disasters and increase accountability through empowering decision making authority to take proper actions.

The IT Governance domain captured the attention of both practitioners and academics. IT Governance is cited as a strategic issue and is usually related to IT decision making/leadership capabilities (Peterson, 2000, Grembergen, 2004a, De Haes, 2009, Grembergen, 2003, Weill and W.Ross, 2004). Associations and regulatory bodies formed IT Governance frameworks with distinct objectives including IT control structure, security, quality of IT services and protection of IT investment(ITGI, 2007, Larsen et al., 2006, Norshidah Mohamed, 2012, ITGI, 2003). All these are vital for endorsing IT sustainability and conveying the organization's objectives. Yet, current literature reflects a lack of maturity and points to diverse and inconsistent concepts of IT Governance(Webb et al., 2006, Denise Ko, 2010). This research aims to provide a conceptual framework for IT Governance in public sectors from both the analysis of theory and practice of IT Governance using Kingdom of Bahrain as a case study. Besides, the research focuses on the 
importance of accountability attributes for IT Governance. The research target participants were selected from public sectors (academic, health, education, allocation of services).

The rest of this paper is divided into six sections; research methodology, case study data collection, IS Organisational Structure, accountability and COBIT, accountability in theory, and finally preliminary results and conclusions.

\section{RESEARCH METHODOLOGY}

The aim of this research is to explore the perspectives and comprehensions of different participants within the subject context that is 'IT Governance' and recognizes that each may have experienced a different understanding of the same situation. To illustrate, this research explores IT Governance Practice from different experiences by approaching multiple cases in the Public Sector. Therefore, IT Governance will be studied in a natural setting or "lived reality", hence, this generated the relevant theory from understanding the IT Governance practice and facilitated the development of the conceptual model. Moreover, a limited amount of research that was conducted in IT Governance in the Public Sector in the Kingdom of Bahrain; therefore this research is exploratory to investigate the maturity level of each case organisation.

In this interpretive study a case study strategy was adopted to investigate IT Governance processes in practice because this will provide the opportunity to investigate IT Governance practice through interviews, questionnaires and document analysis so enabling a rich insight into the different working practices of each case. The research used COBIT assessment tool as a basis for conducting the interviews and questionnaires. The next section illustrates the use of case study strategy and data generation methods.

\section{CASE STUDY DATA COLLECTION}

Case study research is one of the most common method in qualitative research and is suited for information system research as a result of moving from technical to organizational IS related issues (Benbasat et al., 1987, Ebrahim, 2005, Myers and Avison, 2002). In this essence, case study is used in this research for providing an explanation of the observed phenomena (i.e. IT Governance practice and processes), and demonstrating understanding of the subject of investigation in its context and environment (i.e. public sector organisations). The research used multiple methods for data collection because the underlying principle in collection of data in this research is triangulation. In this research, the proposed research questions seeks to identify the maturity level of the IT Governance Practice and the effectiveness of using the selected framework, consequently, interviews, documents analysis and questionnaires are the appropriate data sources used. Further, comparing this research approach to the study as in (Ebrahim, 2005), it can be noted that interviews and document analysis are used and these two methods were considered as the most useful and powerful data sources for interpretive case study research.

This research used the COBIT assessment tool as a basis for conducting semi-structured interviews and questionnaires for 34 processes. Accordingly, and along with both the learning process during this research journey and experience gained from empirical the site data collection process from the first case study, an interest conflict have been noted. In this view, an alternative online survey tool (web-based) was developed. The survey questionnaire was built on selecting 18 most important processes of COBIT. The selection of 18 out of 34 processes was followed by a mapping process to IT Governance domain (see TABLE I). The mapping of COBIT selected 18 processes in to IT Governance areas was informed by the work of ISACA committees COBIT assessment tool (ISACA, 2011). For each maturity level of the 18 selected processes, participants select answers indicating their agreement with the statements, such as, "Not at all", "A little", "Quite a lot" or "Completely". This technique has been used in previous works, such as (Grembergen, 2004a) and (Pederiva, 2003). The electronic version of the surveys has also provided ease of communication and reporting. The selected methods are further illustrated in the next paragraphs.

With regard to the context of this research, the main purpose for conducting interviews in this research was to provide the background information, data and to investigate IT Governance Practice amongst the Public Sector. Throughout this investigation process, the participants were interviewed face-to-face by using a semi-structured interview method to identify the main duties assigned to their position and titles. This was followed with assigning the relevant predetermined questionnaires built based on the COBIT framework, however, the participants freely spoke freely on their practices when asked about issues related to their domain. For instance, (Yin, 2009) introduced this type of case study interview as a 'focused interview' in which a person is interviewed for a short period of time and it remains an openended conversational manner.

Today, the advances in Web-based technology have introduced alternative ways for conducting interviews through the Internet. This procedure was viewed as an alternative interview tool when conflict 
of interest arose with many interviews being postponed as a result of busy schedules in performing face-to-face interviews. Consequently, this led to investigate the web-based software available and transfer the questionnaires. Then, invite the participants through their email addresses to take part in the study and this was successful activity.

Documentation analysis was also a rich source for data collection methods. In the context of this research, firstly, documents provided the basic information for verifying the titles and structure of the organisation. Secondly, documents provided the details to corroborate information from other sources, such as previous research that can be reused, academic literature including books, journal articles and conference papers. In this view, Mendeley a reference manager application used in this research for generating a database of the literature covered during the research journey, provided a good communication tool between supervisors and to search references.

Table 1: Selection of 18 COBIT4.1 processes

\begin{tabular}{|l|l|}
\hline Num & \multicolumn{1}{|c|}{ Process Name } \\
\hline \multicolumn{2}{|l|}{ Plan and Organize } \\
\hline 1 & PO1 Define a strategic IT plan. \\
\hline 2 & PO3 Determine technological direction. \\
\hline 3 & PO5 Manage the IT investment. \\
\hline 4 & PO7 Manage IT human resources. \\
\hline 5 & PO8 Manage quality. \\
\hline 6 & PO9 Assess and manage IT risks. \\
\hline 7 & PO10 Manage projects. \\
\hline Acquire and Implement \\
\hline 8 & $\begin{array}{l}\text { AI2 Acquire and maintain application } \\
\text { software. }\end{array}$ \\
\hline 9 & AI5 Procure IT resources. \\
\hline 10 & AI6 Manage changes. \\
\hline Deliver and Support \\
\hline 11 & DS1 Define and manage service levels. \\
\hline 12 & DS4 Ensure continuous service. \\
\hline 13 & DS5 Ensure systems security. \\
\hline 14 & DS10 Manage problems. \\
\hline 15 & DS11 Manage data. \\
\hline Monitor and Evaluate \\
\hline 16 & ME1 Monitor and evaluate IT performance. \\
\hline 17 & ME2 Monitor and evaluate internal control. \\
\hline 18 & ME4 Provide IT governance. \\
\hline
\end{tabular}

\section{INFORMATION SYSTEM (IS) ORGANIZATIONAL STRUCTURE}

Organisational structure affects the behaviour of the firms through at least two channels. First, structure can have an effect on companywide measures of performance, such as profitability or speed in adopting productivity enhancing innovations. Second the structure of the firm can have consequences for the individuals or operating units that comprise the organisation (DeCanio et al., 2000). Organisational structure can be represented using network models (i.e., networks of social relations).

The structure of the IT function and the position of the decision-making authority in an organisation to a large part determines the efficacy of IT governance (Weill and W.Ross, 2004). For instance, in a study based on a Belgian financial services organisation (private sector) found that the organisation had the $\mathrm{ClO}$ reporting directly to a member of the executive committee; with having an IT strategy committee that operate that operate at the strategy level besides an IT/business steering committee that decided on new investments(Grembergen, 2005). Another case study introduced by (Weill and W.Ross, 2004) on London's Metropolitan Police Service ((OPSI)), the executive body is the Management Board and directly supervises various strategic committees, including Information Management Steering Group. This committee makes recommendations for IT investments and suggests to the Management Board how to start and fund projects, whose proposals are supervised by designated business sponsors right up to completion. Therefore, it is a common to use of steering committee as a popular way of monitoring and reporting progress in all sectors (Sohal and Fitzpatrick, 2002).

In a research study by (Denise Ko, 2010) states that structure can be viewed as how the IT function is carried out; for instance through dedicated responsibilities to an IT executive and relevant IT committee (Grembergen, 2005). Moreover, a decision must be made to locate where IT decision-making authority is located within the organisation (Grembergen, 2004b). In (Weill and W.Ross, 2004) approached IT governance structure as a single most important predator of whether an organisation will derive value from. They viewed structure as "a rational set of arrangements and mechanisms" (Weill and W.Ross, 2004, p.183). Moreover, they introduced structure as to consist of organisational units, roles, and responsibilities for making IT decisions between management and IT committee cooperation. There are three primary modes of IT decisions made around IT: centralized, decentralized and the federal mode (Webb, 2006). The adoption centralized mode indicates to the organization to have the authority to make all IT related decisions, whilst the decentralized mode can take on a number of configurations and 
involves divisional IS and line managers. The federal mode finds IT related decision making distributed between the organisations, divisional IS and line management.

\section{ACCOUNTABILITY AND COBIT}

IT Governance covers five main areas: strategic alignment, value delivery, risk management, resource management (people, money, information, applications and infrastructure) and performance measurement. The most important area that influences all others is the strategic alignment. It focuses on integration of strategies of business and IT by defining, sustaining and controlling a proposition of value that IT delivers to the business. It is also responsible for aligning the IT operations to the operations of the company. The maturity model in the COBIT framework is built in a manner that increases the following attributes through its levels:

- Awareness and communication

- Policies, plans and procedures

- Tools and automation

- Skills and expertise

- Responsibility and accountability

- Goal setting and measurement

These are working beside a set of process control objectives that should be considered together with each process. These are defined as follows:

- PC1 Process Goals and Objectives

- PC2 Process Ownership

- PC3 Process Repeatability

- PC4 Roles and Responsibilities

- PC5 Policy, Plans and Procedures

- PC6 Process Performance Improvement

Hence, the importance of process ownership, roles, responsibly and accountability is embedded into the COBIT framework.

\section{ACCOUNTABILITY IN THEORY}

The adoption of IT Governance is believed to improve organisational accountability, thereby resulting in return on investments (Wessels and Loggerenberg, 2006). This results from aligning business and information technology strategies effectively and efficiently. In the view of Luftman as in (Jerry, 1996) states that "The art of business process design lies in knowing the correct balance between accountability and procedure that is appropriate for a given process" and continues that "In general, the amount of accountability that should be designed into a given process increases with the amount of adaptability required". Weil and
Ross have defined IT Governance as "specifying the decision rights and accountability framework to encourage desirable behavior in using IT" (Weill and W.Ross, 2004). Further, in an attempt to define IT Governance as in (Webb, 2006) authors suggested a structural level framework for corporate governance in respect with (Barrett, 2001). The structural level framework should include:

- Strategic direction

- Policies and procedures

- Control and accountability systems

- Performance management

- Risk management

In (Willson and Pollard, 2009, Jaafar and Jordan, 2011) the authors point out that accountability and control is one of the six facets of IT Governance that is commonly associated with corporate governance or strategic information system planning (SISP) in organizations. Recall that IT governance encompasses dimensions as in (Bowen et al., 2007, Denise Ko, 2010, ITGI, 2007); accordingly, accountability is driven into the organisation by embedding into the IT governance process, i.e., establishing the policies and procedures used to implement the IT investment projects. Yet, there is an increasing amount of literature that suggests that inconsistent and unrealized benefits of IT Governance that is often more theoretical than practical (Wessels and Loggerenberg, 2006). This research will provide some answers to the incongruence in views in IT Governance domain.

The next section covers the algorithm used in calculating the maturity of IT Governance and conclusions.

\section{PRELIMINARY RESULTS}

\subsection{THE ALGORITHM}

The research target participants were selected from public sector organizations based in Kingdom of Bahrain (academic, health, education, allocation of services). The maturity level for each organisation is calculated through adopting a number of functions to facilitate the calculation of the maturity level for each organisation, therefore the data was exported to Microsoft Office Excel. This is based on the COBIT4.1 framework and how the scale was distributed on each maturity level for each process (0-5 scale distributed on scenarios and divided into different statements for 18 processes); TABLE 2 illustrates a sample of results for all levels of process P03. The algorithm used in this research is adopted in previous research by (Pederiva, 2003). 
1. Maturity level compliance value $=$ Sum of statements compliance values /number of maturity level statements

2. Normalize compliance value = Maturity level compliance value/ Total of Maturity level compliance value

3. Weighted Maturity level $=$ Normalize compliance value * Maturity level

Therefore, the maturity level was calculated for each organisation with respect to the 18 processes.

Table 2: Results for process $P 03$ for one case study

\begin{tabular}{|c|c|c|c|c|c|}
\hline 总 & 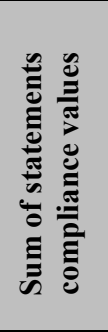 & 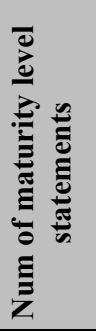 & 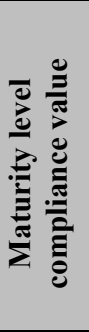 & 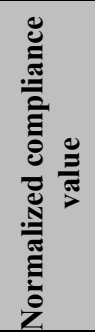 & 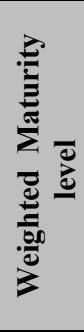 \\
\hline 0 & 0.99 & 3.00 & 0.33 & 0.167 & 0.00 \\
\hline 1 & 0.66 & 2.00 & 0.33 & 0.167 & 0.17 \\
\hline 2 & 1.32 & 4.00 & 0.33 & 0.167 & 0.33 \\
\hline 3 & 1.65 & 5.00 & 0.33 & 0.167 & 0.50 \\
\hline 4 & 2.31 & 7.00 & 0.33 & 0.167 & 0.67 \\
\hline 5 & 0.99 & 3.00 & 0.33 & 0.167 & 0.83 \\
\hline \multicolumn{3}{|c|}{ Total } & 1.98 & 1 & 2.50 \\
\hline \multicolumn{6}{|c|}{$\begin{array}{l}\text { Maturity Model Scale: } \\
0 \text { non-existent, } 1 \text { Initial/ad Hoc, } 2 \text { Repeatable } \\
\text { but Intuitive, } 3 \text { Defined Process, } 4 \text { Managed and } \\
\text { Measurable, } 5 \text { Optimised. }\end{array}$} \\
\hline
\end{tabular}

\subsection{Conclusions}

Improving the Governance maturity needs to refocus on what is necessary to move beyond the current level and requires a clear strategy or plan for the oversight and management of IT activities. This must be discussed with the higher community or steering committee in the organisation as a basis for IT Governance. Then set procedures for the management of key Governance activities.

IT Governance is influenced by different factors that are interconnected together. Some key factors are summarized as follows:

- IT Governance is mainly related to IT decision-making authority. This depends on capability of the organisation and the role of the steering committee.

- Accountability is an important part in IT Governance especially since the organisations are non-profit and IT projects are considered important.

- Although organisations share more or less the same characteristics, they have different IT Governance maturity levels.

- The selected organisations are partially aware of most parts of maturity level statements.

- IT Governance is specific for the organisation and is the responsibility of the board and senior executives to give direction and control over IT.

As a contribution of this research, a conceptual framework model is in a working process. The model presents IT Governance dimensions and constructed from theory and practice.

\section{ACKNOWLEDGMENT}

We would like to thank participants from the five case studies without which their cooperation this research would not have been possible. Their valued contribution and time enabled us in producing these results.

\section{REFERENCES}

(OPSI), O. O. P. S. I. (1998) Data Protection Act (1998).

BARRETT, P. (2001) Corporate Governance More than Good Management. CPA South Australia Annual Congress 2001, "Riding the Next Wave"

BENBASAT, I., GOLDSTEIN, D. K. \& MEAD, M. (1987) The Case Research Strategy in Studies of Information Systems. MIS Quarterly, 11, 369.

BOWEN, P. L., CHEUNG, M.-Y. D. \& ROHDE, F. H. (2007) Enhancing IT governance practices: A model and case study of an organization's efforts. International Journal of Accounting Information Systems, 8, 191-221.

CLEMENTI, S., CARVALHO, T., SUOMI, R., CABRAL, R., HAMPE, J., HEIKKILÄ, A., JÄRVELÄINEN, J. \& KOSKIVAARA, E. ( 2006) Methodology for IT Governance Assessment and Design, Project E-Society: Building Bricks. Springer Boston.

DE HAES, S. V. G., W (2009) An Exploratory Study into IT Governance Implementations and its Impact on Business/IT Alignment. Information Systems Management, 26, pp. 123137.

DECANIO, S. J., DIBBLE, C. \& AMIR-ATEFI, K. (2000) The Importance of Organizational Structure for the Adoption of Innovations. Management Science, 46, 1285-1299. 
DENISE KO, D. F. (2010) Information technology governance: an evaluation of the theorypractice gap. Corporate Governance, Emerald Group Publishing Limited, Vol. 10 pp.662 - 674.

EBRAHIM, Z. A. (2005) The Adoption of eGovernment in the Kingdom of Bahrain. Department of Information Systems and Computing. University of Brunel.

FLYVBJERG, B. \& BUDZIER, A. (2011) Why Your IT Project May Be Riskier Than You Think. Harvard Business Publishing.

GREMBERGEN, S. D. H. W. V. (2005) IT Governance Structures, Processes and Relational Mechanisms: Achieving IT/Business Alignment in a Major Belgian Financial Group. System Sciences, 2005. HICSS '05. Proceedings of the 38th Annual Hawaii International Conference on.

GREMBERGEN, W. V. (2003) Strategies for Information Technology Governance, IGI Publishing Hershey, PA, USA

GREMBERGEN, W. V. (2004a) Strategies for Information Technology Governance University of Antwerp, Belgium, IGI Global.

GREMBERGEN, W. V. (2004b) Strategies for Information Technology Governance University of Antwerp, Belgium, IGI Global.

ISACA (2011) COBIT Self-Assessment Guide: Using COBIT 4.1

ITGI, I. G. I. (2003) Board Briefing on IT Governance, 2nd Edition. IT Governance Institute.

ITGI, I. G. I. (2007) COBIT 4.1, United States of America).

JAAFAR, N. I. \& JORDAN, E. (2011) An exploratory case study of governance practices for information technology (IT) projects in a government-linked company. African Journal Of Business Management, 5, 10667-10706.

JERRY, N. L. (1996) Competing in the Information Age: Strategic Alignment in Practice, Oxford University Press, Inc.

LARSEN, M. H., PEDERSEN, M. K. \& VIBORG ANDERSEN, K. (2006) IT Governance: Reviewing 17 IT Governance Tools and Analysing the Case of Novozymes A/S. System Sciences, 2006. HICSS '06. Proceedings of the 39th Annual Hawaii International Conference on.

MYERS, M. D. \& AVISON, D. (2002) Qualitative Research in Information Systems, London, Sage.

NORSHIDAH MOHAMED, J. K. A. P. G. S. (2012) A conceptual framework for information technology governance effectiveness in private organizations. Information Management \& Computer Security.

PEDERIVA, A. (2003) The COBIT Maturity Model in a Vendor Evaluation Case ISACA.

PETERSON, R. R. (2000) Emerging Capabilities of Information Technology Governance : Exploring Stakeholder Perspectives in Financial Services.

SOHAL, A. S. \& FITZPATRICK, P. (2002) IT governance and management in large Australian organisations. International Journal of Production Economics, 75, 97.

W.ROSS, P. W. J. (2004) IT Govenance: How top performers manage IT decision rights for superior results, Boston, Harvard Business School press.

WEBB, P., POLLARD, C. \& RIDLEY, G. (2006) Attempting to Define IT Governance: Wisdom or Folly? System Sciences, 2006. HICSS '06. Proceedings of the 39th Annual Hawaii International Conference on.

WEBB, P. P., C; RIDLEY, G. (2006) Attempting to Define IT Governance: Wisdom or Folly? System Sciences, 2006. HICSS '06. Proceedings of the 39th Annual Hawaii International Conference on.

WEILL, P. \& W.ROSS, J. (2004) IT Govenance: How top performers manage IT decision rights for superior results, Boston, Harvard Business School press.

WESSELS, E. \& LOGGERENBERG, J. V. (2006) IT governance: theory and practice. Conference on Information Technology in Tertiary Education, Pretoria, South Africa. Citeseer.

WILLSON, P. \& POLLARD, C. (2009) Exploring IT Governance in Theory and Practice in a Large Multi-National Organisation in Australia. Information Systems Management, 26, 98-109.

YIN, R. K. ( 2009) Case Study Research Design and Methods, (SAGE Publications, Inc. 